\title{
FACTORS UNDERPINNING STUDENTS' USE OR NON-USE OF A WRITING CENTRE
}

Aradhna Arbee

University of KwaZulu-Natal

\begin{abstract}
Research has shown that writing centre use has a positive effect on students' performance of specific writing tasks, as well as their overall academic achievement and progression. Yet many writing centres at higher education institutions around the world report low levels of usage of their services. Surprisingly little empirical research has investigated the reasons for this situation. Focusing on students in an undergraduate marketing module at a South African university, the research reported on in this article explored what factors influenced whether or not students made use of the writing centre, as well as potential strategies for increasing the usage of writing centre services. Thematic analysis of participants' written responses to open-ended questions indicated that the major reason for non-use of the writing centre related to time. Misunderstandings around the role of the writing centre were also apparent. Participants' proposed strategies to increase voluntary use of the writing centre included providing evidence of its value to students. The findings offer insight into an overlooked perspective in writing centre research thus far-that of non-users of the service.
\end{abstract}

Keywords: academic literacies, academic writing, discipline, marketing, writing centre

\section{INTRODUCTION}

Writing centres offer students the opportunity to engage in conversation with more experienced writers, who provide guidance on their written drafts (North, 1984). In South Africa, a deficit perspective informed early writing centre work in the 1990s, which focused on remediation aimed at enabling underprepared black students to bridge the gap between school and university (Dison \& Clarence, 2017). Recent writing centre work, however, is generally underpinned by an 'academic literacies' approach, which encompasses a particular epistemology (literacy as social practice) and ideology (transformation) (Lillis \& Scott, 2007), and which accordingly recognises that literacy is influenced by a range of social, cultural, political and disciplinary factors (Dison \& Clarence, 2017). This shift reflects the changing context within which writing centres operate. Globalisation and the massification of higher education have led to rich diversity in the student body (Ganobcsik-Williams, 2012). Furthermore, it is now acknowledged that academic discourse is 'no one's mother tongue' (Mgqwashu, 2001: 62).

Given the importance of writing in higher education, as both a literacy practice and an assessment tool (Lillis, 2001), writing centres can potentially play a significant role in facilitating students' success by helping them get to grips with the academic discourse of their disciplines. Yet a large proportion of the student body either does not use, or underuses, writing centres (LaClare \& Franz, 2013). This article explores the reasons for this situation, as well as potential strategies to address it. 


\section{LITERATURE REVIEW}

The following sections review the literature on the benefits and extent of writing centre usage, factors influencing writing centre usage and strategies for increasing usage.

\section{Benefits of writing centre usage}

Positive outcomes linked to writing centre use include development in terms of writing processes (Bell, 2000) and assessed writing (Archer, 2008). A number of studies have identified a positive relationship between writing centre use and academic performance. For example, more than half of the students who consulted a writing centre 'found their marks had improved, and this improvement was felt across courses' (Archer, 2008: 257). Another study found 'a highly significant association between writing centre attendance and achievement', as well as a significant association between writing centre attendance and progression to the next year of study (Yeats, Reddy, Wheeler, Senior \& Murray, 2010: 499). Furthermore, L2 writers who consulted the writing centre 'scored significantly higher in overall essay writing scores' (Tiruchittampalam, Ross, Whitehouse \& Nicholson, 2018: 1).

\section{Extent of writing centre usage}

Despite these professed benefits, studies in a variety of contexts around the world report that the majority of students do not use writing centres. For example, in the United Kingdom, only $45(5.58 \%)$ of 806 first-year undergraduate business students in an organisational behaviour course at Aston University attended the writing centre, despite the lecturer encouraging attendance (Yeats et al., 2010: 503). In the United States of America (USA), just $10.8 \%$ of the 238 students enrolled for English courses at a community college in southern California sought help at the writing centre (Vazquez, 2008: 65); the Catholic University of America in Washington D.C. attracts moderate traffic to its writing centre (Okuma, 2013: 1); a study of English students at five Mississippi colleges and universities found that most participants did not attend the writing centre (Brown, 2015: 72); just 22\% of the 4204 students entering Temple University in Philadelphia in 2009 visited the writing centre at least once over the next four years (Salem, 2016: 154); and approximately 14\% of the campus population visit Kent State University's writing centre annually (Pfrenger, Blasiman \& Winter, 2017: 23). At Turkey's Sabanci University, approximately 1700 (49\%) of the university's total population of 3470 students use the writing centre in a semester (Tokay, 2012: 420).

The situation is similar in South Africa. Archer's (2008: 251) study involved 40 participants from the University of Cape Town (15\% of all students seen at the writing centre in a semester). This would give an overall figure of 267 students seen over the semester - a very small proportion of the university's total student population, which in 2008 amounted to 22300 (Centre for Higher Education Transformation, 2012: 1). The University of Johannesburg has also experienced low take-up of writing centre services (McKay \& Simpson, 2013: 30).

It appears that low usage of writing centres is a widespread issue (LaClare \& Franz, 2013). Brown (2015: 72) asserts that findings such as those reported above raise larger issues that merit the attention of researchers, in other words, 'determining why students choose to go or not go to the writing center and what might be done in the future to get them to use the writing center more frequently during a semester'. The study reported on in this article aims to contribute to an understanding of precisely such issues. 


\section{Factors influencing writing centre usage}

The literature exploring factors influencing writing centre usage is very limited (Zuma, Popoola \& Makondo, 2016). In particular, the reasons for non-use of writing centres has not received much attention (Salem, 2016).

Perhaps such research is not considered a priority because of capacity constraints, which challenge the ability of writing centres to accommodate more students. As LaClare and Franz (2013: 7-8) assert, 'in circumstances of scant human resources, there is little incentive to attempt to dramatically increase the number of writing center appointments'. In SA, government decisions on university funding following \#FeesMustFall student protests since 2015 (i.e., no fee increase in 2016, a fee increase cap in 2017 and 'fee free' higher education for certain categories of students from 2018), as well as the costs attached to 'insourcing' large numbers of contract staff in recent years (Furlong, 2017), have intensified the financial pressure on universities. The potential implications for writing centre funding, and ability to cope with increased demand, are clear.

At the same time, failure to undertake such research may result in writing centres missing 'opportunities to expand and enhance [their] mission' (LaClare \& Franz, 2013: 8). Resource allocations to writing centres often need to be motivated in relation to relevance and ability to meet objectives (Zuma et al., 2016), both of which could potentially be enhanced through an understanding of the factors affecting students' uptake of writing centre services. Additionally, writing centres need to strengthen their research base in order to be able to engage meaningfully and function optimally (Slemming, 2017).

The limited available literature related to the focus of this article suggests a range of possible factors affecting the usage of writing centres. However, much of this literature is anecdotal. This is in keeping with a lack of empirical writing centre research in general (Bromley, Northway \& Schonberg, 2017), which has led to a call for 'the writing centre community to rely less on anecdote and lore and to push for more research-driven practices' (Wells, 2016: 87). Additionally, some of this literature lacks specific or in-depth focus on writing centres, looking instead at 'self-access centres' (e.g., Allert, 2015; Barrs, 2010) or very briefly considering writing centres as an element of academic support more broadly. It is also possible that contextual features (national, institutional, disciplinary or other) may influence students' writing centre attendance (Santa, 2009; Zuma et al., 2016). For these sorts of reasons, more empirical studies exploring such issues are needed.

Notwithstanding the above caveats, existing literature points to a range of factors potentially influencing writing centre usage. These can be categorised as student-related, lecturer-related, curriculum-related and writing centre-related.

\section{Student-related factors}

Students may not be aware of the writing centre or may not understand the services on offer (LaClare \& Franz, 2013), especially if the centre is new. They may have concerns about possible mismatches between their own and writing centre tutors' styles, the extent to which tutors may change their work and how prescriptive tutors may be (Okuma, 2013). At more established writing centres, attendance may be affected by students' prior experiences there (McKinley, 2010, 2011) and their level of satisfaction with the service received (Bromley, Northway \& Schonberg, 2013). 
Students' conceptions of the writing centre may also affect attendance. For example, some view writing centres as remediation centres (Archer, 2010; McKinley, 2011); attendance may therefore be associated with a 'hint of pathology' (North, 1984: 434) and stigmatised (Salem, 2016). Others may see no need to visit the centre because they view it as simply an editing service, focused on correcting grammar (LaClare \& Franz, 2013; McKinley, 2011; North, 1984).

Students' self-appraisal, confidence in their writing and good academic performance may lead them to believe that it is not necessary to go to the writing centre (McKinley, 2011; Okuma, 2013; Zuma et al., 2016). Motivation is also pertinent (Kirchoff, 2016). For example, Vazquez (2008: 59) identified a positive correlation between 'task value: interest' and helpseeking - students were more likely to seek help from the writing centre if they valued the writing task and its successful completion. Likewise, effective time management may be a factor (Okuma, 2013).

\section{Lecturer-related factors}

The extent to which lecturers encourage use of the writing centre, as well as the extent to which they feel able to handle students' writing needs themselves, may influence usage (McKinley, 2011; Okuma, 2013; Zuma et al., 2016). Other factors include whether lecturers make writing centre attendance mandatory or voluntary, and whether they attach incentives (e.g., class credit or extra points) to attendance and/or penalties (e.g., bad grades) to nonattendance (Bishop, 1990).

\section{Curriculum-related factors}

The level of writing centre use may be related to the amount of writing in the curriculum (LaClare \& Franz, 2013; McKinley, 2011), as well as the extent to which the writing centre is integrated into the curriculum (Arbee \& Samuel, 2015; Barrs, 2010). The nature and importance of the writing task may also affect whether or not students seek the writing centre's help (Okuma, 2013). For example, a challenging assignment may stimulate students to visit the writing centre (Bromley et al., 2013: 25); however, few students are likely to take a multimodal text there (Grouling \& McKinney, 2016: 56). Course demands may lead students to feel that there is no time to visit the writing centre (Bishop, 1990; Clark, 1985; LaClare \& Franz, 2013; McKinley, 2011).

\section{Writing centre-related factors}

The location of, and ease of access to, the writing centre may influence the extent to which it is used (Allert, 2015; Okuma, 2013). Regarding staffing, the availability of peer tutors (LaClare \& Franz, 2013) and the attitude of writing centre staff (Zuma et al., 2016: 108) may affect usage. Service quality is also pertinent (McKinley, 2010).

As noted previously, there are gaps in the existing knowledge on factors influencing writing centre attendance. There is limited empirical work in this research area, particularly in South Africa. Although Zuma et al. (2016) investigated factors affecting writing centre use at a South African university of technology, all participants in their study were writing centre users (attendance was mandatory). As such, an important perspective - that of non-users - is missing. Salem (2016: 151) asserts that 'it is a peculiar feature of writing center research that there has been no meaningful investigation of the decision not to come to the writing center' 
(emphasis in original). The exploratory study reported on in this article began to address this gap by soliciting the views of both users and non-users of a writing centre. Insight into why non-users do not visit the writing centre is crucial in developing appropriate strategies to encourage use.

\section{Strategies for encouraging writing centre use}

In contrast to the studies cited earlier, in which fewer than half of the students under focus consulted writing centres, Morrison and Nadeau (2003: 26) report that $90 \%$ of an undergraduate psychology class at Bryant College in the USA attended the writing centre. They attribute this to an incentive offered in order to promote writing centre use (a five-day extension on the due date for students using the writing centre).

McKinley (2011) describes a number of strategies used to promote a writing centre in Japan. He notes that, while a writing centre orientation was not effective, there was some positive outcome from having writing centre tutors visit classes. However, the best results came from running large group writing workshops.

Maintaining a social media presence and assisting students via Facebook helped to increase the number of face-to-face writing centre visits at a South African university (Ngodwana, 2014: 76). Making students aware of the positive impact of writing centre use on academic performance has also had some success in increasing use (Arbee \& Samuel, 2015).

\section{METHODOLOGY}

The study was conducted at a South African university among students doing an undergraduate marketing module, for which 157 students were registered. Following their submission of a written assignment which students completed in groups of four to six members over a 10-week period, they were requested to complete a questionnaire comprising two open-ended questions. The first one asked them to state their group's reason(s) either for using or for not using the services of the writing centre while working on the assignment. (It is worth noting that students had been encouraged to visit the writing centre during the process of working on their assignments, but it was not mandatory for them to do so.) The second asked them to suggest strategies to encourage greater use of the writing centre. The university granted ethical clearance for the study, and students provided informed consent prior to their participation. Data collection occurred towards the end of 2017.

In total, 33 group assignments were submitted for assessment. Of these, 17 (52\%) had been taken to the writing centre at the draft stage and $16(48 \%)$ had not. Groups that had consulted the writing centre were identified through the writing centre feedback sheet(s) attached to their assignments. A total of 31 completed questionnaires was received. Rambiritch (2018) used a similar methodology (i.e., qualitative evidence from a questionnaire) to explore writing support at a South African university; she gathered data from five writing centre consultants using a questionnaire comprising open-ended questions.

Responses were analysed using thematic analysis, a method for 'identifying, analysing and reporting patterns' in data (Braun \& Clarke, 2006: 79). The analysis adopted an inductive approach. It was not directed by a priori codes; instead, codes were identified purely from the data. This involved reading the data repeatedly to become familiar with the data, detecting 
themes related to the research questions and considering the relationships between identified themes.

\section{FINDINGS AND DISCUSSION}

As this was an exploratory study of an under-researched area, all identified themes are briefly described, rather than focusing on selected themes in more depth (Braun \& Clarke, 2006). Verbatim quotes from participants illustrate the themes. Discussion occurs under each theme and/or at the end of the section.

\section{Reasons for using the writing centre}

Eight themes encompassing students' reasons for using the writing centre were identified: language- and task-related support, quality, perspective, marks, lecturer, experience, incentive and requirement. Each is summarised below.

\section{Language- and task-related support}

The most prevalent theme related to obtaining language- and task-related support. Specifically, students sought assistance with the following aspects: structure/flow, referencing, grammar, formatting/layout, content, style, focus, error identification and general feedback. Most responses mentioned multiple aspects, often straddling language and task issues, as illustrated by the following comment:

We went to check up on our referencing styles, wording, we also asked if we were following the correct format as well as if we have been deviating from the topic given. Mostly references and styles of writing were our main concerns.

Students' language-related concerns encompassed both higher-order (e.g., structure) and lower-order (e.g., referencing) issues. In terms of task-related support, students went to the writing centre 'to gain a better understanding of the assignment' and to ensure that they had properly understood its requirements. They also wanted reassurance that their assignment was 'on track', that they were 'going in the right direction' and that they had 'constructed [the assignment] according to the criteria'.

\section{Quality}

Students wanted to 'deliver [their] best' and went to the writing centre to ensure that their assignment was 'the best possible product of work in terms of expected standards'. In contrast to the narrow task-specific criteria alluded to in the previous theme, however, the standards referred to here related instead to broader conceptions of quality. For example, it was noted that '[the university] has high academic standards', which students wanted to achieve.

\section{Perspective}

Students visited the writing centre to get 'another opinion' or a '3rd party's view' on their work. This enabled them to obtain 'alternative ways to improve [the] assignment'. They also felt that an outside perspective was important because the assignment would 'be viewed without any pre-judgements'. The last comment supports the assertion that the value students place on feedback depends partly on who provides it, and that 'outsider' feedback from 
writing centre consultants may be viewed as unprejudiced and therefore credible (Daniels \& Richards, 2016: 54-55).

Marks

Comments related to this theme revealed that students were motivated to consult the writing centre in order to 'get good marks' for the assignment. Similarly, Vazquez (2008: 80) notes that students expect writing centre attendance to result in better grades.

\section{Lecturer}

Students noted that 'lecturers encourage students to go to the [writing centre]'. They 'were also told that students tend to do better when they've consulted with [the writing centre]'. Prior findings are mixed - while Bromley et al. (2013: 25) identify 'instructor recommendation' as a primary reason for student visits, Yeats et al. (2010: 503) report very low writing centre use despite such recommendation.

\section{Experience}

Previous positive experiences at the writing centre motivated students to go again, as illustrated by this comment: 'The group leader wanted to consult with the [writing centre] as they had helped him with a previous assignment'. Others who have noted the role of past experiences in driving writing centre use include McKinley $(2010,2011)$ and Bromley et al. (2013).

\section{Incentive}

Another finding was that 'there is this idea that students or the group will get an extra $5 \%$ if they consult with the [writing centre]'. Although some lecturers do indeed reward students with bonus marks if they visit the writing centre, that was not the case with this assignment. The reason for this is outlined in the section 'Strategies for increasing writing centre usage', under the theme 'Provide incentives'.

\section{Requirement}

The (erroneous) belief that 'it was a requirement for the assignment' that students visit the writing centre also led to student visits. As noted earlier, however, writing centre use was optional.

The above findings in relation to students' reasons for writing centre use are largely in line with those of Bromley et al. (2013: 25), whose analysis of writing centre exit surveys at three higher education institutions in the USA revealed that 'five primary reasons for student visits are consistent: improvement of writing in general, improvement of grades, instructor recommendation, challenging assignments, and assurance that students are on the right track'. Four of these reasons were apparent in the current study's findings; however, writing centre users in this study did not identify 'challenging assignments' as a reason for visiting the centre. 


\section{Reasons for not using the writing centre}

Eight themes related to non-use of the writing centre were identified: time, not helpful, no bookings, group issues, did not need assistance, got assistance elsewhere, not compulsory and lack of awareness. A summary of each follows.

\section{Time}

Despite the assignment having been handed out on the first day of the semester, and students having had 10 weeks to complete it, many indicated that they had not been to the writing centre for time-related reasons.

Managing time effectively appeared to be an issue, with responses revealing that some groups had not had drafts ready early enough to allow sufficient time to consult the writing centre before the submission deadline. Others had left it too late to make a booking and could not secure an appointment when they enquired close to the submission date. Comments associated with this issue include the following:

Our assignment took us very long... hence the use of the [writing centre] fell away.

Did not get chance to book on time.

Also, poor time management resulted in very little time being left towards seeking help.

Another issue related to time was workload. Students indicated that they had heavy workloads in all their modules, with several assignments due close together, which prevented them going to the writing centre, e.g., 'We did not have sufficient time to visit the [writing centre] as we had 3 other assignments to complete in the same time frame.'

Not helpful

Some groups did not go to the writing centre because they did not think that it would be useful to do so. A couple of responses revealed that they perceived the writing centre to be 'only for grammar purposes'. Others cited previous negative experiences at the centre:

From previous experience, each tutor told the group something different when it came to referencing - no consistency.

Tutor came 20 mins late and rushed through the assignment.

No bookings

Comments linked to this theme noted that students had intended to visit the writing centre, but were unable to secure a booking. This may have been related to poor time management by students, or to limited writing centre capacity.

\section{Group issues}

Group-related reasons for not consulting the writing centre were that it was difficult to schedule a time where all group members were available' and 'group members submitted 


\section{A Arbee}

their work so late which led us not to book'. There was some overlap with time-related issues here.

\section{Did not need assistance}

Some students did not feel that they required the writing centre's assistance. One group stated: 'In the first semester we consulted for another assignment and we kept notes from that consultation session'. Similarly, another response noted that, having been to the writing centre previously, students felt that they 'now understand what is required...when doing an assignment'.

As North (1984: 38) points out, writing centres look beyond the particular text that is the student's current concern, addressing instead 'the process by which it is produced' so as to 'produce better writers, not better writing'. The comments above may therefore reflect success on the part of the writing centre in this regard.

A possible alternative interpretation, however, could be that these comments reflect a 'study skills' approach on the part of the students, in that they appear to view writing as a generic transferable skill (Lea \& Street, 2006). An 'academic literacies' approach, however, views writing as a social practice that acquires meaning based on context, audience and purpose (Lea \& Street, 2006), implying that writing conventions differ across assignments and disciplines. This is something that lecturers and the writing centre could address with students, to encourage greater uptake of writing centre services on a more regular basis, rather than as a once-off exercise. It would be important, however, to ensure that the support provided does go beyond the generic (Dison \& Clarence, 2017).

\section{Got assistance elsewhere}

Related to the previous theme, students indicated that they preferred to consult academic development officers, rather than writing centre tutors, about the assignment. Academic development officers are postgraduate students based within particular disciplines, who are able to provide undergraduate students with support related to module content in addition to academic writing support. Explaining the preference for consulting academic development officers, students noted that they 'found it better than going to the [writing centre]' because they 'got help with answering the question and understanding it, rather than getting help with grammar and punctuation which do not help answer the question in its entirety'.

Similarly, McKinley (2010: 25) notes that some students do not go to the writing centre because they feel that they get better assistance from their lecturers. This raises questions around the type of support (language- and/or task-related) provided by the writing centre and module lecturers, as well as the extent of collaboration between them.

\section{Not compulsory}

Another finding revealed that students did not consult the writing centre because 'we were told that it is not compulsory for us to go'. The debate around mandatory use is addressed under the theme 'Make use compulsory' in the section 'Strategies for increasing writing centre usage'. 


\section{Lack of awareness}

Finally, it was claimed that 'not everybody knows about the existence of the [writing centre] and that's why they don't go there'. Awareness campaigns may therefore be useful in increasing usage.

As previously mentioned, non-use of writing centres has received very limited empirical research attention. However, there are some similarities between previous findings and those of this study. The major reason for non-use of the writing centre in this study related to time, which is in keeping with what Bishop (1990) and McKinley (2011) have found, suggesting that strategies to encourage writing centre use should address the time factor. Possibilities include embedding writing centre support within scheduled class time, staggering assignment due dates across modules and extending assignment submission deadlines for writing centre users.

The tension and balance between language- and task-related support also came through quite strongly in the data. Students' misperceptions around the writing centre's role need to be addressed.

Unlike previous studies, this study identified some group-related issues that influence writing centre use, due to its focus on a group assignment.

\section{Strategies for increasing writing centre usage}

The eight themes summarised below outline the strategies proposed by students to encourage greater use of the writing centre, i.e., make use compulsory, revise/improve service, highlight benefits, provide evidence of benefits, provide incentives, promote services, apply penalties and 'other'.

\section{Make use compulsory}

A widespread theme related to making writing centre use 'compulsory' or 'mandatory'. Students felt that attending a writing centre consultation should be 'a must and not an option' and that 'assignments should not be accepted if students did not take it to the [writing centre]'.

Literature, however, reveals contestation around the notion of mandatory writing centre usage (Citti, 2015; Clark, 1985; North, 1984; Salem, 2016; Thaiss, Brauer, Carlino, GanobcsikWilliams \& Sinha, 2012; Wells, 2016). Writing centres generally prefer students to attend by choice, not only because they are then more motivated and get more out of the sessions, but also to avoid the 'stigma of remediation' which may be attached to mandatory visits; indeed, choice is considered to be an important part of many writing centres' 'professional selfdefinition' (Salem 2016: 152). There is also the question of whether writing centres would have the capacity to accommodate all students. While acknowledging the pedagogical and administrative challenges of mandatory visits, Citti (2015) highlights the potential benefits, including the opportunity to reach and help specific student populations (such as firstgeneration and first-year students) who might not seek help on their own. 


\section{Revise/improve service}

Another prevalent theme focused on improving the nature and/or 'quality of the service' provided by the writing centre. Examples of comments linked to this theme include:

The tutors need to be more encouraging and do more than just checking grammar.

Encourage better time management by [writing centre] tutors, often the entire hour is used for the first page.

Several comments indicated that students viewed the writing centre as grammar-focused, whereas they wanted content-related support. Information posted by the writing centre on the university notice system (e.g., making students aware of their services and advertising tutor vacancies) revealed that the support offered at the centre focused on understanding academic writing conventions, improving grammar and structure, as well as argumentation and referencing. Similarly, Daniels and Richards (2016: 53) note that tutors at Stellenbosch University's Writing Lab work with 'structure, argumentation and referencing, and not directly with the subject matter of the assignment', leading some students to consider the help 'generic and superficial'. The role of the writing centre should therefore be clarified up front during consultations.

Regarding availability, students felt that 'more time slots' should be made available for writing centre consultations during the semester and that the centre should 'open certain days of holidays'. The assignment was due shortly after students returned from a mid-semester break (during which the writing centre shuts down). As it may be easier for group members to attend a consultation together during the break, without the need to work around differing timetables, and as assignments in various modules tend to be due just after the break, this is something that the centre could consider.

\section{Highlight benefits}

Students felt that lecturers and the writing centre should 'make students more aware of the advantages' of writing centre use early in the semester, with regular reminders during the semester. A typical comment was that 'from the start of each semester lecturers should advise students to use the [writing centre] and tell them about the benefits of using it and how it could help them'.

\section{Provide evidence of benefits}

In contrast to the previous theme, this theme revealed that simply informing students of the potential benefits was not enough to increase writing centre use. What was additionally required was 'proof that the [writing centre] can be of MAJOR help' (participant's emphasis). For example, it is important to 'illustrate the benefits by showing [students] previous assignments of those who have been and those who have not and the difference between marks'. Another suggestion was for students to get feedback directly from 'students who attended as compared to those who did not'.

As noted earlier, a number of published studies have identified a link between writing centre use and academic performance. Lecturers could make students aware of such research. However, they should also try to determine the relationship between writing centre use and academic achievement in their own contexts, if possible, as their students may find this more Per Linguam 2020 36(1):32-46 http://dx.doi.org/10.5785/36-1-881 
persuasive. Lecturers could also invite previous students to class to share their experiences of writing centre use; alternatively, they could share anonymous comments from previous writing centre evaluations with students.

\section{Provide incentives}

Students suggested that lecturers reward them for using the writing centre. The proposed incentive (mentioned in all comments linked to this theme) was to 'allocate marks for consulting the [writing centre]'. Students recommended that the value of these bonus marks be between one and five percent of the total assignment mark. Another proposal was to link bonus marks to the number of group members attending a writing centre consultation, to encourage more members to attend. Ideally, all members should attend the consultation together, but this does not always happen.

I once offered a mark-based incentive to encourage writing centre use, but stopped doing so upon discovering that many students went simply to qualify for the bonus marks and then ignored the feedback obtained during the consultation. An alternative may be to allow an extension on the assignment due date for those consulting the writing centre (Morrison \& Nadeau, 2003). This would be especially pertinent considering that students' most frequently cited reason for not using the writing centre was time. However, this too may be subject to the limitation noted above in relation to mark-based incentives.

\section{Promote services}

Students suggested that the writing centre 'advertise more to get student attention' and 'use other forms other than emails to reach out to students'. For example, 'a spokesperson from the [writing centre] could visit students at a lecture to give tips for assignments and basically advertise their services in the lecture'. As noted previously, the writing centre tends to use the university notice system and emails to reach students; however, students who do not regularly access these may miss such communications. Lecture visits should therefore be used to a greater extent.

Apply penalties

Some students proposed penalties for not using the writing centre, specifically that 'marks should be deducted from assignments that were not checked by the [writing centre]'. Similar views were expressed by participants in Bishop's (1990) study.

\section{Other}

Other proposals included running a seminar 'to make students understand the dynamics of professional and academic writing' - McKinley (2011) found large group workshops most effective - and encouraging students 'to not start their assignment late'. Finally, one response asserted that students should take more responsibility for their work: 'We (students) need to take more pride in our work and we must also understand that the [writing centre] offers greater knowledge and experience to help us do our assignments.'

\section{CONCLUSION}

The findings presented provide some insight into the views of non-users of the writing centre, thus far a neglected perspective in the literature. Findings revealed that non-use was linked to Per Linguam 2020 36(1):32-46 http://dx.doi.org/10.5785/36-1-881 
a range of factors, primarily time; accordingly, strategies to increase use should address such factors. Misunderstanding of the writing centre's role was also apparent in the data; this should be clarified for students. Providing evidence of the value of using writing centres is another strategy that may prove effective in increasing writing centre use.

The study reported on in this article was small-scale and exploratory in nature, focusing on students in one module at one South African university. As such, there is scope for further research involving more students, as well as different disciplines and types of writing tasks, as there could conceivably be discipline-related and task-specific factors at play in influencing writing centre use. Finally, a different method of data collection may enable deeper exploration of the issues. Liggett, Jordan and Price's (2011) taxonomy of methodologies in writing centre research provides a useful overview of the wide range of methodological options available.

\section{REFERENCES}

ALLERT, K. 2015. Considering context: The importance of specific institutional and learner contexts when researching the set up of a self-access centre. Studies in Self-Access Learning, 6(2):231-244.

ARBEE, A \& MA SAMUEL. 2015. The writing centre: A site for discursive dialogue in management studies. South African Journal of Higher Education, 29(5):48-69.

ARCHER, A. 2008. Investigating the effect of writing centre interventions on student writing. South African Journal of Higher Education, 22(2):248-264.

ARCHER, A. 2010. Challenges \& potentials for writing centres in South African tertiary institutions. South African Journal of Higher Education, 24(4):495-510.

BARRS, K. 2010. What factors encourage high levels of participation in a self-access centre? Studies in Self-Access Learning Journal, 1(1):10-16.

BELL, JH. 2000. When hard questions are asked: Evaluating writing centers. The Writing Center Journal, 21(1):7-28.

BISHOP, W. 1990. Bringing writers to the center: Some survey results, surmises, and suggestions. The Writing Center Journal, 10(2):31-44.

BRAUN, V \& V CLARKE. 2006. Using thematic analysis in psychology. Qualitative Research in Psychology, 3(2):77-101.

BROMLEY, P, K NORTHWAY \& E SCHONBERG. 2013. How important is the local, really? A cross-institutional quantitative assessment of frequently asked questions in writing center exit surveys. The Writing Center Journal, 33(1):13-37.

BROMLEY, P, KJ NORTHWAY \& E SCHONBERG. 2017. Review: Strategies for writing centre research, by Jackie Grutsch McKinney. The Writing Center Journal, 36(1):237244.

BROWN, SG. 2015. Campus writing centers, student attendance and change in student writing performance. Unpublished $\mathrm{PhD}$ dissertation, University of Southern Mississippi.

CENTRE FOR HIGHER EDUCATION TRANSFORMATION. 2012. Cross national performance indicators for the University of Cape Town. Available from https://www.chet.org.za/resources/cross-national-performance-indicators-universitycape-town [Accessed: 9 February 2018].

CITTI, J. 2015. A case for compulsion? On requiring whole-class writing center visits. Available from http://writing.wisc.edu/blog/?p=6140 [Accessed: 13 February 2017]. 
CLARK, IL. 1985. Leading the horse: The writing center and required visits. The Writing Center Journal, 5/6(2/1):31-34.

DANIELS, S \& R RICHARDS. 2016. From autopsy to autonomy in writing centres: Postgraduate students' response to two forms of feedback in a health professions education module. Per Linguam, 32(3):48-59

DISON, L \& S CLARENCE. 2017. Introduction. In S Clarence \& L Dison (Eds), Writing centres in higher education: Working in and across the disciplines. Stellenbosch: Sun Press. 5-16.

FURLONG, A. 2017. Insourcing at universities: Uneven progress. Available from https://www.news24.com/SouthAfrica/News/insourcing-at-universities-unevenprogress-20170315 [Accessed: 13 June 2018].

GANOBCSIK-WILLIAMS, L. 2012. Reflecting on what can be gained from comparing models of academic writing provision. In C Thaiss, G Brauer, P Carlino, L GanobcsikWilliams \& A Sinha (Eds), Writing programs worldwide: Profiles of academic writing in many places. Fort Collins and Anderson: The WAC Clearinghouse and Parlor Press. 499-511.

GROULING, J \& JG MCKINNEY. 2016. Taking stock: Multimodality in writing centre users' texts. Computers and Composition, 41:56-67.

KIRCHOFF, L. 2016. Motivation in the writing centre: A peer tutor's experience. Journal of Academic Writing, 6(1):31-40.

LACLARE, E \& T FRANZ. 2013. Writing centers: Who are they for? What are they for? Studies in Self-Access Learning Journal, 4(1):5-16.

LEA, MR \& BV STREET. 2006. The 'academic literacies' model: Theory and applications. Theory into Practice, 45(4):368-377.

LIGGETT, S, K JORDAN \& S PRICE. 2011. Mapping knowledge-making in writing center research: A taxonomy of methodologies. The Writing Center Journal, 33(2):50-88

LILLIS, TM. 2001. Student writing: Access, regulation, desire. London: Routledge.

LILLIS, TM \& M SCOTT. 2007. Defining academic literacies research: Issues of epistemology, ideology and strategy. Journal of Applied Linguistics, 4(1):5-32.

MCKAY, TM \& Z SIMPSON. 2013. The space between: Pedagogic collaboration between a writing centre and an academic department. Perspectives in Education, 31(4):27-42.

MCKINLEY, J. 2010. English language writing centres in Japanese universities: What do students really need? Studies in Self-Access Learning Journal, 1(1):17-31.

MCKINLEY, J. 2011. Group workshops: Saving our writing centre in Japan. Studies in SelfAccess Learning Journal, 2(4):292-303.

MGQWASHU, EM. 2001. Stumbling along in a cart that's been put before the horse: the predicament of English second language students in the Departments of English at the HWUs. Scrutiny 2: Issues in English Studies in Southern Africa, 6(2):63-66.

MORRISSON, JB \& J NADEAU. 2003. How was your session at the writing center? Preand post-grade student evaluations. The Writing Center Journal, 23(2):25-42.

NGODWANA, K. 2014. Experiences of students regarding the use of Facebook for mentoring: A case of a writing centre. Unpublished MPhil dissertation, University of Cape Town.

NORTH, SM. 1984. The idea of a writing centre. College English, 46(5):433-446.

OKUMA, T. 2013. Understanding student perceptions of the writing center - A conversation between a student, a writing center instructor, and a director/professor. Available from http://writing.wisc.edu/blog/?p=3489 [Accessed: 13 February 2017]. 
PFRENGER, W, RN BLASIMAN \& J WINTER. 2017. 'At first it was annoying': Results from requiring writers in developmental courses to visit the writing center. Praxis: A Writing Center Journal, 15(1):22-35.

RAMBIRITCH, A. 2018. A social justice approach to providing academic writing support. Educational Research for Social Change, 7(1):46-60.

SALEM, L. 2016. Decisions...decisions: Who chooses to use the writing center? The Writing Center Journal, 35(2):147-171.

SANTA, T. 2009. Writing centre tutor training: What is transferable across academic cultures? Zeitschrift Schreiben. Available from http://www.zeitschriftschreiben.eu/Beitraege/santa_Tutor_Training.pdf [Accessed: 23 May 2014].

SLEMMING, F. 2017. The place of education theories in writing centres: Why this makes for significant research. In S Clarence \& L Dison (Eds), Writing centres in higher education: Working in and across the disciplines. Stellenbosch: Sun Press. 19-34.

THAISS, C, G BRAUER, P CARLINO, L GANOBCSIK-WILLIAMS \& A SINHA (Eds). 2012. Writing programs worldwide: Profiles of academic writing in many places. Fort Collins and Anderson: The WAC Clearinghouse and Parlor Press.

TIRUCHITTAMPALAM, S, A ROSS, E WHITEHOUSE \& T NICHOLSON. 2018. Measuring the effectiveness of writing center consultations on L2 writers' essay writing skills. Languages, 3(4):1-13.

TOKAY, D. 2012. A writing center journey at Sabanci University, Istanbul. In C Thaiss, G Brauer, P Carlino, L Ganobcsik-Williams \& A Sinha (Eds), Writing programs worldwide: Profiles of academic writing in many places. Fort Collins and Anderson: The WAC Clearinghouse and Parlor Press. 417-427.

VAZQUEZ, L. 2008. What motivational factors influence community college students' tendency to seek help from the writing center? Unpublished DEd dissertation, University of Southern California.

WELLS, J. 2016. Why we resist 'leading the horse': Required tutoring, RAD research, and our writing center ideals. The Writing Center Journal, 35(2):87-114.

YEATS, R, P REDDY, A WHEELER, C SENIOR \& J MURRAY. 2010. What a difference a writing centre makes: A small scale study. Education + Training, 52(6/7):499-507.

ZUMA, N, T POPOOLA, \& L MAKONDO. 2016. Accessing success through the writing centres at a university of technology. Journal of Communication, 7(1):103-110.

\section{BIOGRAPHICAL NOTE}

Aradhna Arbee is a lecturer in Marketing in the School of Management, Information Technology and Governance at the University of KwaZulu-Natal. Her research interests include marketing communications and Marketing education. Email: arbee@ukzn.ac.za 